\title{
Novel Polycatenar Mesogens Containing 1,3,4-thiadiazole.
}

\author{
E. Y. Elgueta ${ }^{a^{*}}$, M. L. Parraa ${ }^{a}$ J. A. Ulloa ${ }^{a}$. \\ ${ }^{a}$ Facultad de Ciencias Químicas, Departamento de Química Orgánica, Universidad de Concepción, Casilla \\ 160-C, Concepción, Chile.
}

*e-mail corresponding author: elelguet@udec.cl

Keywords: Polycatenar, Columnar liquid crystal, Hydrogen bonding, Enantiotropic.

\section{INTRODUCTION}

Currently there is great interest in the design and synthesis of new non-conventional liquid crystalline materials, to generate new mesophases and molecular organizations. The policatenar mesogens are very interesting, because they have an intermediate molecular architecture, situated between rod-like and discotic mesogens, and exhibit both calamitic and columnar liquid crystal phases [1]. Varying the chain length of polycatenar compounds can change the mesogenic behaviour from that of the calamitic rod-like materials to that of columnar materials [2]

In this work, we report the synthesis, characterization and mesomorphic properties of novel polycatenar liquid crystal. In these cases, it was suggested that the driving force for the columnar phase is microphase segregation between the rigid-rod core and the flexible chains, and the $\pi-\pi$ stacking between the $\pi$-conjugated aromatic rings. The synthetic route is shown in the scheme 1.

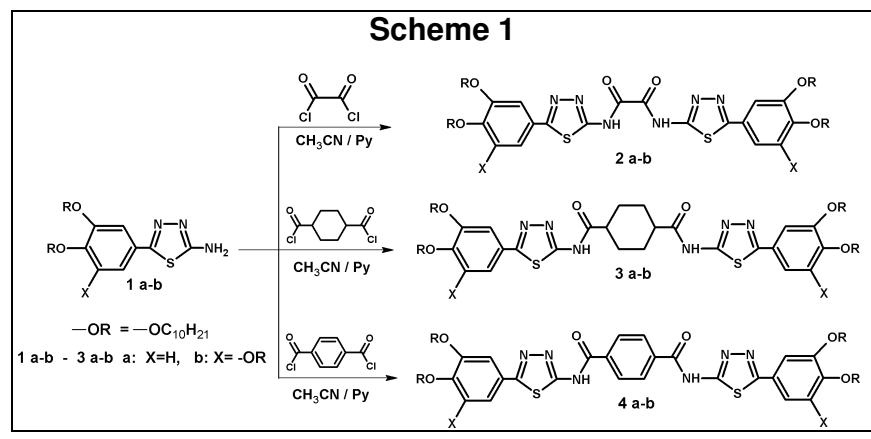

\section{RESULTS AND DISCUSSION}

All the compounds of the series $\mathbf{2 a - b}, \mathbf{3 a - b}$ and $\mathbf{4 a - b}$ exhibit mesomorphic properties. The homologues 2a, 3a and $\mathbf{4 a}$ have the broadest mesomorphic ranges and homologues $\mathbf{2 b}, \mathbf{3 b}$ and $\mathbf{4 b}$ has a more narrow mesomorphic range. In each case an enantiotropic columnar mesophase is observed. The columnar phase was determined from textural observations by thermal microscopy under a polarizing microscopy. Representative microphotographs of the texture observed for the compounds $\mathbf{2 a}, \mathbf{3 b}, \mathbf{4 a}$ and $\mathbf{4 b}$ is shown in figure 1 . The transition temperatures and phase behavior of the new materials are given in Table 1.

Figure 1. Optical textures of the columnar mesophase.

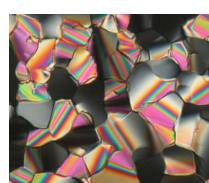

a)

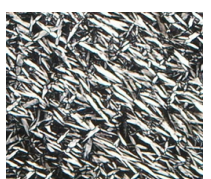

b)

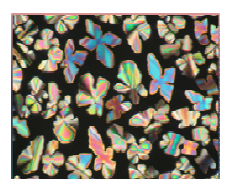

c)

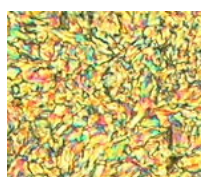

d)
Table 1. Transition temperatures $\left({ }^{\circ} \mathrm{C}\right)$ for compounds of series $\mathbf{2} \mathbf{a}-\mathbf{b} \mathbf{-} \mathbf{4} \mathbf{a}-\mathbf{b}$.

\begin{tabular}{|c|c|c|}
\hline Compounds & $\begin{array}{c}\text { Transition } \\
\text { Temperatures } \\
\left({ }^{\circ} \mathrm{C}\right) \text { Heating scan }\end{array}$ & $\begin{array}{c}\text { Mesomorphic } \\
\text { ranges }\left({ }^{\circ} \mathrm{C}\right)\end{array}$ \\
\hline $2 a$ & Cr $130 \mathrm{Col}_{\mathrm{x}} 264 \mathrm{I}$ & 134 \\
\hline $2 b$ & Cr $134 \mathrm{Col}_{x} 194 \mathrm{I}$ & 60 \\
\hline $3 a$ & $\mathrm{Cr} 92 \mathrm{Col}_{\mathrm{x}} 213 \mathrm{I}$ & 121 \\
\hline $3 b$ & Cr 132 Col $_{x} 195$ I & 63 \\
\hline $4 a$ & Cr $200 \mathrm{Col}_{x} 285 \mathrm{I}$ & 85 \\
\hline $4 b$ & Cr 197 Col $_{x} 215$ I & 18 \\
\hline
\end{tabular}

\section{CONCLUSION}

In conclusion, we have succeeded in the design, synthesis and mesophase characterization of a novel class of polycatenar columnar liquid crystals based on 1,3,4-thiadiazole derivatives.

\section{ACKNOWLEDGEMENTS}

This work was supported by FONDECYT (1100140), CONICYT, FULLBRIGHT and "Dirección de Investigación" of the University of Concepción.

\section{REFERENCES}

${ }^{1}$ Wang, H. T.; Zhang, F. L.; Bai, B. L.; Zhang, P.; Shi, H. S.; Yu, D. Y.; Zhao, Y. F.; Wang, Y.; Li, M.; Liq. Cryst. 2008, 35, 905.

${ }^{2}$ Sultana, N. H.; Kelly, S. M.; Mansoor, B.; O’Neill, M.; Liq. Cryst. 2007, 34, 1307. 